\title{
Food plants and foraging distances for the native bee Lasioglossum sordidum in Christchurch Botanic Gardens
}

\author{
Della G. Bennet ${ }^{1}$, Dave Kelly ${ }^{1 *}$ and John Clemens ${ }^{2}$ \\ ${ }^{1}$ Centre for Integrative Ecology, School of Biological Sciences, University of Canterbury, Private Bag 4800, Christchurch 8140 \\ ${ }^{2}$ Christchurch Botanic Gardens, Christchurch City Council, PO Box 73036, Christchurch 8154 \\ *Author for correspondence (Email: dave.kelly@canterbury.ac.nz)
}

Published online: 12 October 2017

\begin{abstract}
With concerns about declines in pollinating bee species worldwide, there is renewed interest in solitary native bee species and their role in pollination services. We studied the foraging preferences and foraging distances of Lasioglossum sordidum (Halictidae), New Zealand's smallest solitary bee, in urban Christchurch. Lasioglossum sordidum were abundant within the Christchurch Botanic Gardens. Pollen samples taken from 40 bees at each of two nest sites were identified using a pollen reference collection from the sites. Bees were collecting pollen from both native and exotic plants. In total, pollen from 23 different plant taxa was found, but $96 \%$ came from five taxa: Asteraceae (65\%), Hebe spp. (16\%), Aesculus spp. (8\%), Yucca baccata (3\%) and Taraxacum officinale (3\%). Individual bees usually specialised in a few pollen types, with $74 \%$ of bees having $>90 \%$ of a single pollen type and a mean of 2.6 pollen types per bee. The minimum flight distances to the nearest sources of each pollen type were typically $70-250 \mathrm{~m}$. These easily overlooked bees may be assisting more in general pollination services given the diversity of plant taxa from which the bees were collecting pollen, the variation from bee to bee in the plant taxa collected, and the sometimes considerable minimum foraging distances exhibited.
\end{abstract}

Keywords: Aesculus; Asteraceae; flower constancy; Halictidae; Hebe; pollination

\section{Introduction}

Pollination by animals is important for seed production in many plants and has a strong positive effect on seed production in a range of crops used worldwide for direct human consumption (Klein et al. 2007). There is concern that production of agricultural crops that rely on various bee species for pollination could face declines adversely affecting associated industries (Rader et al. 2009; Howlett \& Donovan 2010; Lentini et al. 2012; Newstrom-Lloyd 2013) due to declines in bee populations. Globally, honeybees are adversely affected by the spread of the Varroa destructor mite and Colony Collapse Disorder, although the latter has not been recorded in New Zealand (Stevenson et al. 2005; Donovan 2007; Rader et al. 2009), and a decline in food source availability (AllenWardell et al. 1998). Within New Zealand, control measures have been implemented to contain the spread of $V$. destructor within commercial hives (Stevenson \& Smale 2005), but feral honeybees have been dramatically reduced in abundance (HD Wilson, pers. comm.) and Donovan (2007) expected colonies in both the North and South Islands of New Zealand to die. These issues have focused attention on the roles of native pollinators, which were shown in a global study to be important even to crop pollination (Garibaldi et al. 2013). Rader et al. (2009) suggest further study of the biology of unmanaged pollinators is warranted, having established that Brassica rapa var. chinensis (pak choi) pollination services could potentially replace those provided by the honeybee.

Historically, New Zealand lacked any long-tongued or large social bees (Newstrom \& Robertson 2005) traditionally known to provide pollination services, but still had a wide range of indigenous pollen and nectar feeding species. These include 41 short-tongued bees (Donovan 1980, 2007; Read et al. 1990), moths, butterflies, beetles, flies (Goulson 2003; Newstrom \& Robertson 2005), birds (Kelly et al. 2010), bats (Godley 1979; Arkins et al. 1999) and lizards (Whitaker 1987). Since the arrival of Europeans in the early nineteenth century, eight large bee species, five of them social, have been introduced to New Zealand to assist in the pollination of agricultural plants (Donovan 2007; Howlett \& Donovan 2010). These exotic bees also visit the flowers of numerous native plants (Butz Huryn 1995). New Zealand native bees provide a significant contribution to the pollination of native plants (Kelly et al. 2006; Donovan 2007) and also appear to be supporting pollination of some commercial crops (Donovan 2007; Rader et al. 2009; Howlett \& Donovan 2010; Howlett et al. 2011).

Lasioglossum sordidum (Halictidae) is one of New Zealand's most common ground-nesting bees and is found throughout the country (Quinn 1984; Donovan 2007). Its adults are more numerous than those of all other native bees on the east of the South Island (Donovan 2007). This bee is classed as solitary although several females may forage from the same nest, and multiple generations could be active at the same time. This suggests some limited social organisation (Donovan 1980, 2007). Fertilised females overwinter in nests, emerging as early as late winter as the ground begins to warm (Donovan 1980, 1983, 2007). New males and females start appearing in late spring and are active through warmer months although each bee probably lives no longer than 6-8 weeks (Donovan 1980, 2007). Their length (4.9-6.1 mm; Donovan 2007) is considerably smaller than that of the introduced honeybee (Apis mellifera), which measures around 12-13 $\mathrm{mm}$ (Donovan 1980). Lasioglossum sordidum regularly go unnoticed owing to their small, fly-like appearance (Donovan 2007). They are small and agile, and will push their way into 
floral tubes or open flowers, sometimes leaving very little of the bee exposed (Godley 1979; DB pers. obs.). In general, their short tongues do not restrict their foraging for pollen (Goulson 2003), although this is not the case for some plant species e.g. Medicago sativa (Donovan 2007). Being polylectic, L. sordidum forage pollen from a wide range of ornamental plants, both native and introduced to New Zealand, as well as introduced crop plant species (Donovan 2007).

Nests consist of branching tunnels penetrating to a depth of around $400 \mathrm{~mm}$ within a fine-grained substrate (Donovan 1980; Quinn 1984; Wojcik \& McBride 2012). Hundreds of female bees can nest within a few square metres of bare soil (Donovan 2007). Pollen is carried by the females on the scopae on their hind legs, thorax and to some degree on their abdomen (Donovan 1980, 2007; Quinn 1984).

Information on the foraging range of bee species, especially solitary native bees, is contributing to a better understanding of the potential pollination services they could provide as well as the formulation of strategies for their conservation (Gathmann \& Tscharntke 2002; Goulson 2003; Kim et al. 2006; Greenleaf et al. 2007; Zurbuchen et al. 2010). Various methods can be used to study these issues, including radar, feeder-training, and bee relocation. Another method involves the identification of pollen grains collected from individual bees and then measuring the distance to the nearest plant of the species collected (Beilenson 1991; Greenleaf et al. 2007).

The aims of this study were: (1) to identify the plant taxa, as much as possible to the species level, of the pollen being collected by L. sordidum in an urban botanic garden where there was a diverse and known assemblage of woody and herbaceous plants of mixed native and exotic origin; (2) given the diversity of pollen sources, to discover whether individual L. sordidum collect pollen from multiple plant taxa or show a preference in a foraging bout for pollen of a single plant taxon or a few plant taxa, that is, exhibit specialisation in their pollen harvesting (MacIvor et al. 2014); (3) if individual bees specialise, whether this is constant throughout the population or varies among individuals; and (4) to establish the minimum foraging distance travelled by $L$. sordidum to these known floral resources and to establish if this is related to the number and proportion of pollen taxa collected.

\section{Methods}

We worked in the Christchurch Botanic Gardens (hereafter the Botanic Gardens) (43 $\left.31.9^{\prime} \mathrm{S}, 172^{\circ} 37.0^{\prime} \mathrm{E}\right)$, central Christchurch, New Zealand, which contains a wide range of exotic and native flowering plants. A preliminary survey showed that there were many L. sordidum nesting sites in the Botanic Gardens, both in highly visible locations within areas of bare compacted soil, and beneath the canopies of vegetation and under mulches. Bee activity was most noticeable during the warmth of the middle of the day, and most sampling was subsequently undertaken between $1100 \mathrm{~h}$ and $1300 \mathrm{~h}$ during sunny episodes rather than when clouds created shade.

Aggregations of nesting sites were chosen for study within the area known as the pinetum. This contained a collection of mixed coniferous trees with a predominantly grass understorey in which there were occasional flowering plants of Taraxacum officinale. We undertook our research in this area because, unlike most of the Botanic Gardens, it experienced low foot traffic from the public, reducing disturbance to bees and their nests. The area is bordered to the north, west and south by roads, and beyond these by Hagley Park's closely mown sports fields that extend a distance of 400-900 m devoid of plants other than sports turf species bordered by European wind-pollinated trees (and flowering cherries, which had finished flowering at the time of our sampling). This location meant that the Botanic Gardens would be the closest source for any pollen type occurring in them, although the bees could have flown greater distances in other directions to visit private gardens beyond Hagley Park. Over 99\% of the pollen types identified on bees was found on plants growing in the Botanic Gardens. Some of the seven rare unidentified pollen types could have come from beyond Hagley Park.

We selected two aggregations of nesting sites $145 \mathrm{~m}$ apart for sampling. The car park site was located in a shrub garden adjoining a car park, and the Monterey pine site near the base of a mature Pinus radiata (or Monterey pine) tree. Each of these contained numerous nest tunnels located in patches of exposed ground. Forty pollen-carrying female bees per site were captured individually as they returned to their nests at the car park (23-24 November 2012) and Monterey pine sites (24-25 November 2012). During these 3 days, minimum and maximum air temperatures were $10-12^{\circ} \mathrm{C}$ and $20-22^{\circ} \mathrm{C}$, respectively.

Digital maps were used to measure the straight-line distance (to the nearest $m$ ) between each potential pollen source plant and each nesting site, described as the pollen mapping technique by Greenleaf et al. (2007). These were taken as the minimum distance a bee would need to fly to collect that particular pollen (referred to below as the minimum foraging distance). These minimum foraging distances do not take into account deviations each bee could have made between its nest and the pollen source(s).

\section{Pollen collection and identification}

Bees were placed into plastic vials $(40 \mathrm{~mm}$ long x $10 \mathrm{~mm}$ diameter) where they either released their pollen spontaneously or required chilling and rewarming, which resulted in grooming and the prompt release of pollen. All bees were held until the end of the sampling period to prevent resampling of the same bee, and then released back at their respective collection site. Six bees were collected and photographed using a Leica MZ10F stereo-microscope (16x magnification) with Leica DFC310FX camera. Identifications were made using voucher specimens (Simon Litchwark, University of Canterbury) and the key in Donovan (2007).

A pollen reference collection was constructed using specimens collected from plants in flower in the surrounding area between 22 and 27 November 2012. The locations of these plants were recorded in the Botanic Gardens plant database and the locations were checked by reference to experienced field staff working in the grounds. Map references and photographic records were taken for each plant sample. The pollen reference collection included 113 species or cultivars from 50 plant families ( 21 native and 23 exotic families, and six of mixed native and exotic origin). Examination of pollen from five different taxa from the family Asteraceae indicated that we would not be able to distinguish between such pollens subsequently collected from bees, except in the case of Taraxacum officinale.

All pollen specimens (from bees and plants) remained refrigerated until being mounted on slides in gelatin-fuchsin gel (Robertson et al. 2005). Pollen grains were collected from each flower or the interior of each plastic tube by rolling a small cube of gel (c. $7 \times 7 \times 5 \mathrm{~mm}$ ) across the surface (Howlett 
et al. 2011). This cube was melted on to a microscope slide and covered with a cover slip. Once cool and labelled, the pollen was examined using a Leica DM5000B compound microscope (630x magnification) and Leica DFC310FX camera. A photographic reference collection was produced for all plant pollens. This collection was used together with published identification keys to identify the pollen grains collected from L. sordidum (Cranwell 1953; Moar 1993). Three hundred randomly selected bee pollen grains were counted per slide and identified (24 000 pollen grains in total). Slides, insect specimens and pollen were deposited at the School of Biological Sciences, University of Canterbury. Remaining loose pollen is available for further identification techniques including acetolysing (LE Newstrom-Lloyd, pers. comm.).

\section{Analysis}

We used linear regression to test for a relationship between distance to the nearest plant of each pollen type and overall mean abundance of that pollen type across all bees. The regression was run in $\mathrm{R}$ version 3.1.1 ( $\mathrm{R}$ Development Core Team 2014). We tested pollen types per bee, predicted from either (1) abundance of the most common pollen type on that bee, or (2) distance to the nearest plant of the dominant pollen type on that bee, using poisson GLMs in R to allow for the integer response variable. The data were not overdispersed.

We were interested in the number of different plant species that each bee had been visiting. This analysis was constrained by the Asteraceae (non-Taraxacum) pollen type being common but spanning at least four possible species, so there was an unknown amount of cryptic diversity in the number of plant species visited. We used subsets of the data to estimate the importance of this cryptic diversity. We hypothesized that Lasioglossum bees regard the various species within the Asteraceae pollen type as different, since they vary in flower colour, shape and size (see results section). We also hypothesized that the number of individual flower types visited at one time by individual Lasioglossum bees is constrained by memory limitations on efficient flower handling (Waser 1986). Under those conditions, if a single bee which carried Asteraceae pollen typically collects from multiple Asteraceae species, it should also carry significantly fewer non-aster pollen types. Since the multiple aster species are counted as a single pollen type, these bees should have fewer recorded pollen types in total. In contrast, if single bees with Asteraceae pollen typically collect from only one aster, the number of non-aster types should not be constrained, and aster-collecting bees should not carry significantly fewer pollen types in total. We tested this by comparing pollen types per bee in two groups: bees with 0-7\% Asteraceae pollen type $(n=21)$ and bees with $14-100 \%$ of this pollen type $(n=59)$. The number of pollen types per bee were compared using a poisson GLM run in $\mathrm{R}$.

\section{Results}

The pollen collected from bees contained 23 distinct pollen taxa (Table 1). These included native, exotic, and mixed taxa. Seven pollen types from bees could not be identified, although all of these were rare (combined total $0.34 \%$ of the pollen count; Table 1). Pollens of 90 taxa in the reference collection of plants that were in flower at the time were not detected in the pollen collected by the bees.

Asteraceae pollen was by far the most abundant pollen type, making up $65 \%$ of all pollen (Table 1, Fig. 1), and only seven of the 80 bees carried no Asteraceae pollen. It was not possible to identify the pollen to individual taxa from which reference collections had been made (Table 3) except for Taraxacum officinale. Although T. officinale was present in 39 bee samples ( $49 \%$ of bees) and was the fifth most common pollen type, it was a small part of the total pollen count (3.1\%) (Table 1). The second most common pollen was of the native genus Hebe $(16 \%)$, followed by the two introduced genera Aesculus and Yucca (8\% and 3\%, respectively). Our test for cryptic pollen diversity within the Asteraceae pollen type found little support for our hypothesis. We found no significant difference in the number of apparent pollen types per bee for the 21 bees with $0-7 \%$ Asteraceae pollen (mean of 2.7 pollen types per bee) versus the 59 bees with $14-100 \%$ Asteraceae pollen (mean 2.6 pollen types per bee; poisson GLM, $\mathrm{Chi}^{2}$ $=0.068, \mathrm{df}=1, \mathrm{P}=0.79$ ). This is consistent with each bee typically collecting mainly from a single species within the Asteraceae family.

Several members of the family Myrtaceae (mainly native species and the Australian Melaleuca steedmanii) were in flower at the time the study was undertaken. However, only one bee carried any Myrtaceae pollen (1.3\% of its pollen was the native Metrosideros umbellata plus 1\% of other Myrtaceae that could not be identified to finer taxonomic level).

Although there was a wide range of plant taxa available from which to collect pollen, in general, individual bees collected pollen predominantly from a single plant taxon. Thus,

Table 1. The percentage of different pollen taxa present in samples collected from $L$. sordidum bees at two nest sites in the Christchurch Botanic Gardens in November 2012.

\begin{tabular}{lccc}
\hline & $\begin{array}{c}\text { Monterey } \\
\text { pine site }(\%)\end{array}$ & $\begin{array}{c}\text { Car park } \\
\text { site }(\%)\end{array}$ & $\begin{array}{c}\text { Mean } \\
(\%)\end{array}$ \\
\hline Asteraceae & 60.57 & 69.00 & 64.79 \\
Hebe spp. & 21.16 & 11.31 & 16.24 \\
Aesculus spp. & 4.77 & 11.69 & 8.23 \\
Yucca baccata & 2.37 & 3.96 & 3.17 \\
Taraxacum officinale & 3.71 & 2.54 & 3.13 \\
Linaria purpurea & 2.50 & 0 & 1.25 \\
Mazus radicans & 1.12 & 0.95 & 1.04 \\
Euphorbia glauca & 1.95 & 0 & 0.98 \\
Lychnis flos-jovis & 1.11 & 0.30 & 0.71 \\
Unidentified 7 & 0.25 & 0.01 & 0.13 \\
Unidentified 2 & 0.20 & 0 & 0.10 \\
Podocarpus spp. & 0.08 & 0.03 & 0.06 \\
Aruncus dioicus & 0.09 & 0 & 0.05 \\
Unidentified 1 & 0 & 0.08 & 0.04 \\
Unidentified 5 & 0.08 & 0 & 0.04 \\
Bulbinella hookeri & 0 & 0.07 & 0.035 \\
Myrtaceae & 0 & 0.03 & 0.015 \\
Metrosideros umbellata & 0 & 0.03 & 0.015 \\
Unidentified 4 & 0.03 & 0 & 0.015 \\
Fuchsia spp. & 0.01 & 0 & 0.005 \\
Arthropodium cirratum & 0.01 & 0 & 0.005 \\
Unidentified 3 & 0.01 & 0 & 0.005 \\
Unidentified 6 & 0 & 0.01 & 0.005 \\
\hline & & &
\end{tabular}


a. Monterey pine site

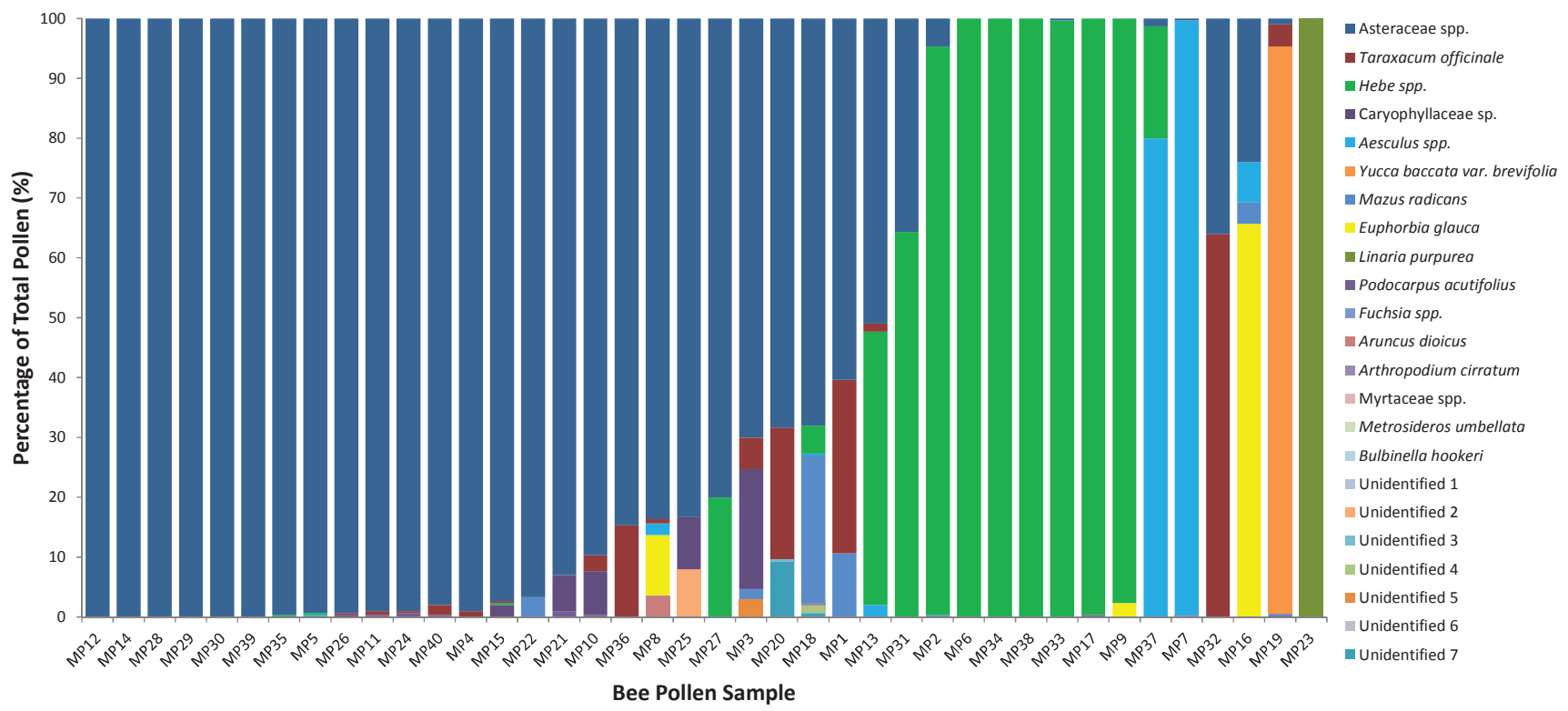

b. Car park site

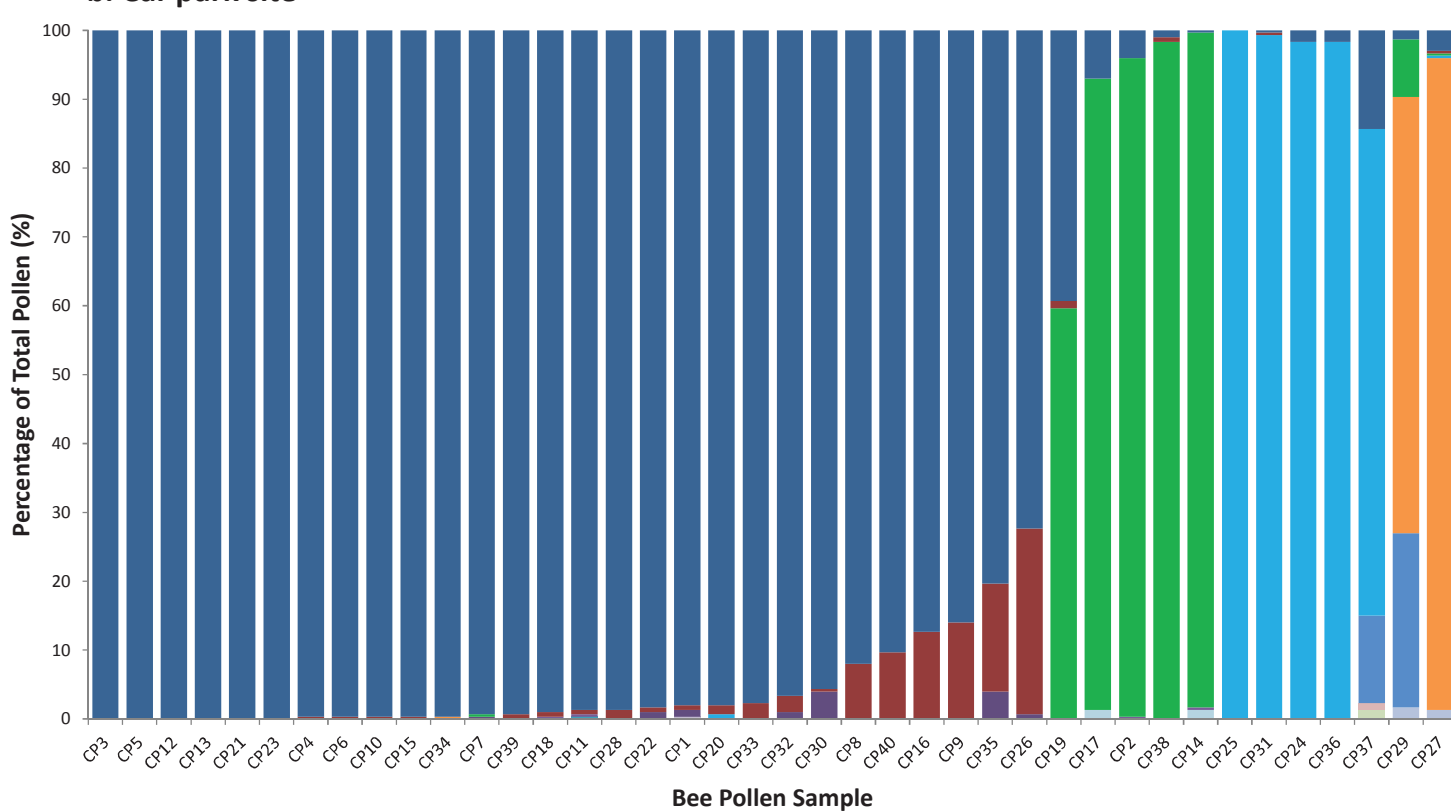

Asteraceae spp.

- Taraxacum officinale

- Hebe spp.

- Caryophyllaceae sp.

- Aesculus spp.

- Yucca baccata va.r brevifolia

- Mazus radicans

Euphorbia glauca

- Linaria purpurea

- Podocarpus acutifolius

- Fuchsia spp.

- Aruncus dioicus

- Arthropodium cirratum

Myrtaceae spp.

$\square$ Metrosideros umbellata

Bulbinella hooker

- Unidentified 1

- Unidentified 2

- Unidentified 3

- Unidentified 4

Unidentified 5

$\square$ Unidentified 6

- Unidentified 7

Figure 1. Percentages of different plant taxa represented in pollen collected from 40 individual L. sordidum bees sampled at each of (a) Monterey pine and (b) car park nesting sites within the Christchurch Botanic Gardens.

Table 2. Numbers of L. sordidum bees that had collected most ( $>90 \%)$ of pollen of a single pollen type during November 2012, Christchurch Botanic Gardens.

\begin{tabular}{lccc}
\hline Pollen type & \multicolumn{2}{c}{ Number of bees with $>90 \%$ pollen of that type } \\
\cline { 2 - 4 } & Monterey pine site & Car park site & Total \\
\hline Asteraceae & 16 & 24 & 40 \\
Hebe spp. & 7 & 4 & 11 \\
Aesculus spp. & 1 & 4 & 5 \\
Yucca baccata & 1 & 1 & 2 \\
Linaria purpurea & 1 & 0 & 1 \\
Mixed load & 14 & 7 & 21 \\
\hline Total number of bees & 40 & 40 & 80 \\
\hline Mean pollen types per bee & 2.63 & 2.55 & 2.59
\end{tabular}


59 out of 80 individual bees $(74 \%)$ had greater than $90 \%$ of pollen from one plant taxon on returning to their nests, and 17 of the $80(21 \%)$ were carrying only a single plant taxon pollen (Table 2).

However, the bees exhibiting this specialised collecting behaviour differed in the plant taxon chosen for collecting (Table 2). For instance, half the bees collected solely or predominantly ( $>90 \%$ of pollen collected) from the Asteraceae (40 bees; Fig. 1). Contrastingly, 14\% of the bees collected solely or predominantly from Hebe, and 6\% from Aesculus (11 and five bees, respectively; Fig. 1).

The importance of this between-bee variability is most clearly shown for Linaria purpurea (purple toadflax). Pollen of this species represented $1.25 \%$ of all pollen but this resulted from a single bee carrying pollen only of L. purpurea (Monterey pine site, Fig. 1). No L. purpurea pollen was found on any other bee sampled from either site. Similarly, although not as exclusively, Yucca baccata constituted $95 \%$ of the pollen on two bees (Fig. 1), and $63 \%$ and $0.3 \%$ of the pollen on two more bees, yet pollen of this species was not found on any of the other 76 bees (Table 2). Because of this pattern of collecting, the overall proportion of total pollen collected of a particular plant taxon was mainly influenced by the proportion of bees that foraged largely or wholly upon that particular plant taxon. This also showed that $L$. sordidum individually specialise on one or a few flower types in each foraging bout, but because individual bees specialise on different flower types, collectively the population was foraging on a wide range of plant species.

Nonetheless, 21 of the $80 \mathrm{~L}$. sordidum bees $(26 \%)$ had mixed loads of pollen from several different plant taxa (mixed load defined as the most common pollen type being $<90 \%$ of the pollen). For example, one bee had pollen from the Asteraceae, Hebe and Aesculus, as well as from Mazus radicans, Arthropodium cirratum, and small quantities of two unidentified plant pollens; another carried predominantly Yucca baccata pollen along with pollen of $T$. officinale, M. radicans and Podocarpus (Fig. 1). On average, bees were carrying pollen of 2.6 plant taxa (Table 2) and the number of pollen taxa was inversely related to the abundance of the most common pollen in each sample (Fig. 2 ; $\mathrm{Chi}^{2}=10.57$, df $=1, \mathrm{P}=0.001)$. However, even the mixed loads were usually dominated by few pollen taxa. Counting only pollen taxa that made up at least $10 \%$ of a bee's total pollen load, 16 bees had two taxa, two bees had three, and the other 62 had only a single pollen taxon contributing $>10 \%$. However, if individual bees had visited multiple different species of Asteraceae or Hebe this would not have been detected with our methods.

There was no relationship between the minimum foraging distance for each site to a pollen source of a particular plant taxon and the proportion of that pollen of that taxon in the harvested pollen (Fig. 3 ; regression $\mathrm{F}_{1,20}=0.11, \mathrm{P}=0.74$ ). In other words, pollen was collected from plant taxa in proportions that bore no relation to the minimum distance the bees would have had to fly to those sources. This lack of relationship is exemplified by pollen of $T$. officinale making only a small contribution to pollen collected overall $(3.1 \%$, Table 1$)$ even though plants of this taxon were flowering as close as $2 \mathrm{~m}$ from each of the nesting sites. Conversely, pollen of Aesculus was found in $8 \%$ of the samples even though the closest plants were $173 \mathrm{~m}$ from the car park and $235 \mathrm{~m}$ from the Monterey pine nest sites (the greatest minimum foraging distance recorded). Moreover, Asteraceae other than T. officinale made up 65\% of all pollen but were at a minimum foraging distance of $86-168$ $\mathrm{m}$ (Table 3 ). Several of the other principal pollen taxa were

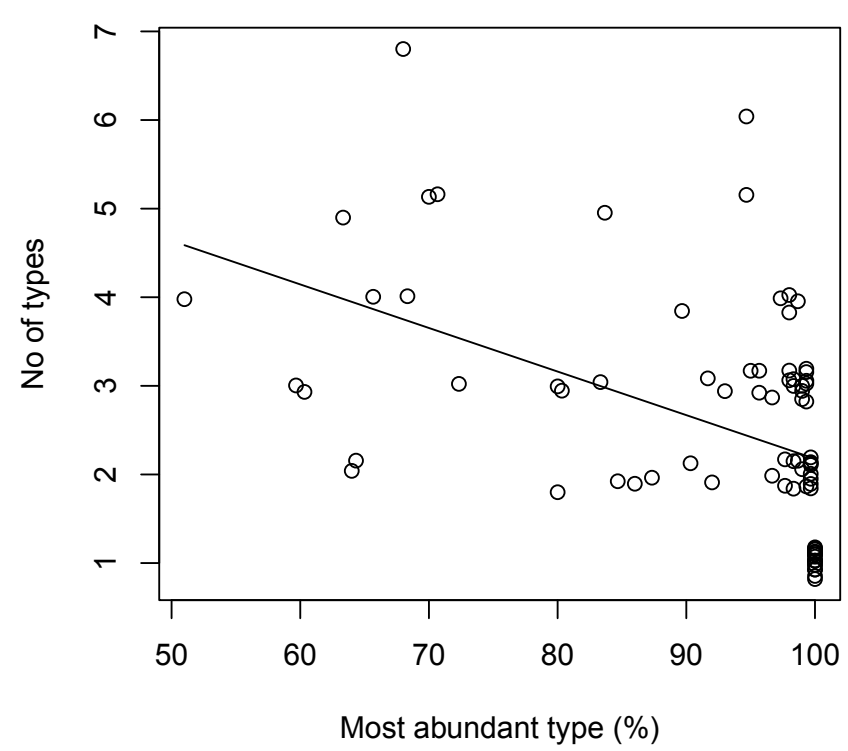

Figure 2. The relationship between the abundance (\%) of the most common pollen taxon and the total number of pollen taxa in each sample from 80 individual L. sordidum bees from the Christchurch Botanic Gardens. The regression was significant (poisson GLM, $\left.\mathrm{Chi}^{2}=10.57, \mathrm{df}=1, \mathrm{P}=0.001\right)$. The data are jittered vertically to reveal overlapping data points.

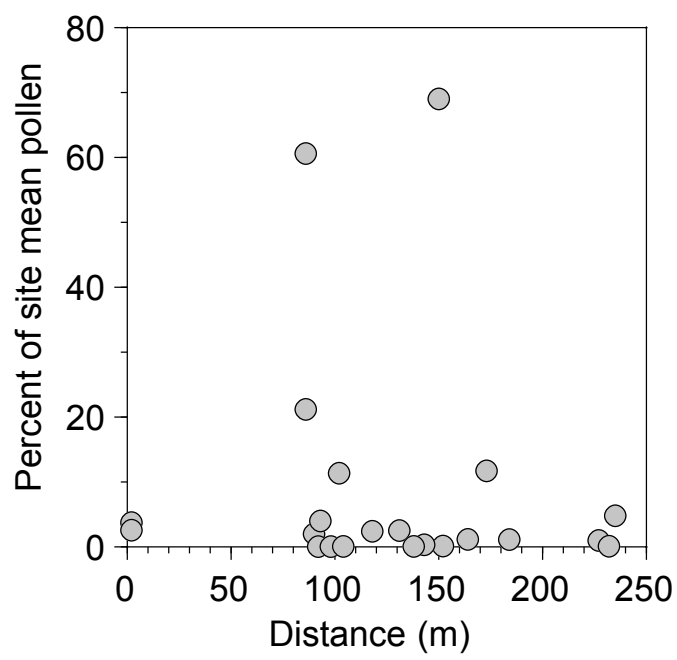

Figure 3. Relationship between minimum foraging distance to a pollen taxon and the proportion of that pollen (\%) in pollen samples from $40 \mathrm{~L}$. sordidum bees, for each of two nest sites in the Christchurch Botanic Gardens. The regression was not significant $\left(\mathrm{F}_{1,20}=0.11, \mathrm{P}=0.74\right)$.

sourced well over $100 \mathrm{~m}$ from the nests, e.g. species of Yucca, Linaria, and Mazus (Table 3). There was also no relationship between distance to nearest plant of the dominant pollen type on a bee and the number of pollen types found on that bee (poisson regression; $\mathrm{Chi}^{2}=0.481$, $\mathrm{df}=1, \mathrm{P}=0.49$ ), so bees did not collect more (or fewer) pollen types if they had flown further. It should be noted that these are all minimum distances to the nearest single plant; bees were almost certainly travelling further than this to reach multiple individuals of measured species and/or more distant species where a pollen type covered more than one species. 
Table 3. Minimum distances ( $\mathrm{m}$ ) between the L. sordidum nest sites and the closest source plant for pollen types found on the bees. Dashes indicate a pollen type not found on bees from that nest site. The Asteraceae species, apart from Taraxacum, could not be separated using pollen morphology but we list the closest flowering examples of that family to the nest sites.

\begin{tabular}{|c|c|c|c|}
\hline \multirow[b]{2}{*}{ Family } & \multirow[b]{2}{*}{ Species } & \multicolumn{2}{|c|}{ Distance (m) to: } \\
\hline & & Monterey pine site & Car park site \\
\hline Agavaceae & Yucca baccata & 118 & 93 \\
\hline Asteraceae & $\begin{array}{l}\text { Brachyglottis spp. } \\
\text { Olearia spp. } \\
\text { Pachystegia insignis } \\
\text { Ozothamnus leptophyllus } \\
\text { Taraxacum officinale }\end{array}$ & $\begin{array}{c}90 \\
111 \\
105 \\
86 \\
2\end{array}$ & $\begin{array}{c}158 \\
152 \\
168 \\
150 \\
2\end{array}$ \\
\hline Asphodelaceae & $\begin{array}{l}\text { Arthropodium cirratum } \\
\text { Bulbinella hookeri }\end{array}$ & $\begin{array}{c}98 \\
-\end{array}$ & - \\
\hline Caryophyllaceae & Lychnis flos-jovis & 184 & 143 \\
\hline Euphorbiaceae & Euphorbia glauca & 90 & - \\
\hline Myrtaceae & $\begin{array}{l}\text { Kunzea ericoides } \\
\text { Lophomyrtus bullata } \\
\text { Leptospermum scoparium } \\
\text { Melaleuca steedmanii } \\
\text { Metrosideros umbellata }\end{array}$ & $\begin{array}{l}- \\
- \\
- \\
- \\
-\end{array}$ & $\begin{array}{l}257 \\
153 \\
257 \\
104 \\
138\end{array}$ \\
\hline Onagraceae & $\begin{array}{l}\text { Fuchsia excorticata } \\
\text { Fuchsia procumbens }\end{array}$ & $\begin{array}{c}104 \\
92\end{array}$ & $\begin{array}{l}- \\
-\end{array}$ \\
\hline Phrymaceae & Mazus radicans & 164 & 227 \\
\hline Plantaginaceae & $\begin{array}{l}\text { Hebe spp. } \\
\text { Linaria purpurea }\end{array}$ & $\begin{array}{c}86 \\
131\end{array}$ & $\begin{array}{c}102 \\
-\end{array}$ \\
\hline Rosaceae & Aruncus dioicus & 152 & - \\
\hline Sapindaceae & Aesculus spp. & 235 & 173 \\
\hline
\end{tabular}

\section{Discussion}

Lasioglossum sordidum showed a capacity to forage relatively large distances, foraging on pollen sources quite distant from their nesting sites, and the overall contribution of a plant species to the pollen total was unrelated to minimum distances to that species. This could have been driven by preferences for some flower types over others, and preference for mass flowering rather than small scattered plants (Primack 1978). The bees had strong preferences, with 23 pollen types found on bees but 90 locally flowering species not detected on the sampled bees. Although the grassed area surrounding the nesting sites contained exotic T. officinale (Asteraceae), these small herbaceous plants were present at low density, possibly providing limited foraging opportunities. Contrastingly, seven bees flew beyond numerous native and exotic plants to reach and forage predominantly on the large flower crops of Aesculus trees. Beil et al. (2008) observed a similar result with Lasioglossum calceatum, which travelled 700-1000 m to collect pollen from Aesculus hippocastanum. The relative abundance of pollen available for harvest on host plant taxa was not quantified in our study so the apparent preferences exhibited by the bees could have reflected variation in pollen supply at the time.

The foraging range of $L$. sordidum is comparable with other small bee species, which on average travel approximately $250 \mathrm{~m}$ (Wojcik \& McBride 2012). A flight intercept study comparing different insects found L. sordidum travelling 200 $\mathrm{m}$, but none was recorded within traps set at $300 \mathrm{~m}$ (Rader et al. 2011). Zurbuchen et al. (2010) suggested that a foraging distance of a few hundred metres (100-300 m) was typical for most individuals in a population of small bees, although some could travel much further. This maximum foraging range is comparable to our data (Table 3), although our distances are minima and bees could have been going much further. These combined results may provide a good estimate for the average foraging range of $L$. sordidum and provide a better understanding of their foraging landscape (Greenleaf et al. 2007).

Individual L. sordidum typically demonstrated flower constancy by apparently selecting pollen primarily of one or two types on any foraging session, consistent with previous reports (Primack 1983; Waser 1986; Beilenson 1991). This may be to maximise foraging efficiency, given some limits on the ability of bees to remember and handle multiple flower types within one session (Waser 1986). Nonetheless, numerous floral rewards were being collected across the whole population, because of variation between individual bees in their chosen flower types at the time of sampling. We reiterate that within some of our common pollen types, particularly Asteraceae, we have no way of knowing if individual $L$. sordidum bees were visiting multiple different species within the same pollen type. However, the test of pollen types per bee for bees with and without Asteraceae suggested this cryptic diversity might be small. Further work on this (e.g. using DNA to identify pollen to plant species) would be very helpful.

There have been several reports of L. sordidum foraging on members of the Asteraceae, including Pachystegia insignis (Donovan 2007; Webber et al. 2012; DB pers. obs.), Brachyglottis spp. (Webber et al. 2012; DB pers. obs.) and Olearia spp. (Primack 1983; Donovan 2007). Hebe spp. are also reported as providing numerous foraging opportunities for L. sordidum (Primack 1983; Donovan 2007; Webber et al. 2012). Lasioglossum sordidum have previously been noted visiting Bulbinella, members of Caryophyllaceae, Aesculus (Donovan 2007) and Mazus (Primack 1983), although there are 
no previous reports of them foraging on Linaria purpurea, Yucca baccata or Aruncus dioicus according to the comprehensive data presented by Donovan (2007).

The relatively small amounts of pollen from the Myrtaceae in samples collected in the current study was surprising because Webber et al. (2012) had earlier recorded L. sordidum visiting species from this family at a nearby location, both exotic (Callistemon polandii and Leptospermum nitidum) and native (Leptospermum scoparium and Lophomyrtus $\times$ ralphii). Others have also reported L. sordidum foraging upon Kunzea ericoides, Leptospermum scoparium, Lophomyrtus spp. and Melaleuca spp. (Primack 1978, 1983; Donovan 2007; Webber et al. 2012).

Native bees are often outnumbered by $A$. mellifera on various floral resources (Goulson 2003; Donovan 2007). Moreover, A. mellifera starts foraging earlier in the day than the native bee populations (Goulson 2003), so food resources may be depleted before $L$. sordidum start foraging. However, this competition is not thought to limit the successful foraging of L. sordidum (Donovan 1980, 2007).

Agricultural intensification and other land use changes can reduce suitable nest and foraging sites within certain areas while creating other opportunities for bees (Klein et al. 2007). During a development and relocation project for Leioproctus huakiwi larvae from Akaroa, Banks Peninsula, to Lincoln, mid-Canterbury, L. sordidum individuals promptly occupied the holes that had been deliberately prepared within the bare soil of the new L. huakiwi nesting site (Donovan et al. 2010), and L. sordidum bees have been studied visiting various crops, including kiwifruit, blueberries, onion, and pak choi (Macfarlane \& Ferguson 1983; Macfarlane 1992; Howlett et al. 2005, 2011; Rader et al. 2009, 2012). While it is beyond the scope of our work to extend our findings to specific agricultural landscapes, our results add to those of others from garden situations (Greenleaf et al. 2007; Wojcik \& McBride 2012) and indicate patterns of pollen collecting that might have relevance to the design of habitat enhancements for L. sordidum in these settings.

We successfully identified over $99 \%$ of pollen grains taken from the sample L. sordidum bees returning to two nesting sites in the Botanic Gardens. While individuals were specialists, the collective populations of $L$. sordidum were generalist foragers as individuals varied in their plant choices, travelling at least $70-250 \mathrm{~m}$ to collect from a range of both native and exotic pollen types. Although there could be further cryptic foraging diversity in pollen taxa containing multiple plant species, even the flower diversity confirmed here shows that Lasioglossum sordidum visit the flowers of a wide range of plant species. These native bees are so small they are often overlooked, but they could be making an important contribution to pollination.

\section{Acknowledgements}

We thank Dean Pendrigh, Mark Davis, Guillaume Jacob and David Barwick (Christchurch Botanic Gardens) for helping with plant identification and the initial location of bee nesting sites, Simon Litchwark (University of Canterbury) for help with insect identification, and the Canterbury Branch of the Royal Society of New Zealand and University of Canterbury for funding the Summer Scholarship to DGB. Three anonymous referees provided helpful comments on the draft.

\section{References}

Allen-Wardell G, BernhardtP, Bitner R, BurquezA, Buchmann S, Cane J, Cox PA, Dalton V, Feinsinger P, Ingram M, Inouye D, Jones CE, Kennedy K, Kevan P, Koopowitz H, Medellin R, Medellin-Morales S, Nabhan GP, Pavlik B, Tepedino V, Torchio P, Walker S1998. The potential consequences of pollinator declines on the conservation of biodiversity and stability of food crop yields. Conservation Biology 12: 8-17.

Arkins AM, Winnington AP, Anderson S, Clout MN 1999. Diet and nectarivorous foraging behaviour of the shorttailed bat (Mystacina tuberculata). Journal of Zoology (London) 247: 183-187.

Beil M, Horn H, Schwabe A 2008. Analysis of pollen loads in a wild bee community (Hymenoptera: Apidae) - a method for elucidating habitat use and foraging distances. Apidologie 39: 456-467.

Beilenson JP 1991. A gift of mistletoe. White Plains, NY, Peter Pauper Press Inc. 32 p.

Butz Huryn VM 1995. Use of native New Zealand plants by honey bees (Apis mellifera L.): a review. New Zealand Journal of Botany 33: 497-512.

Cranwell LM 1953. New Zealand pollen studies. The monocotyledons. Bulletin of the Auckland Institute and Museum 3: 1-91.

Donovan BJ 1980. Interactions between native and introduced bees in New Zealand. New Zealand Journal of Ecology 3: 104-116.

Donovan BJ 1983. Comparative biogeography of native Apoidea of New Zealand and New Caledonia. GeoJournal 7: $511-516$.

Donovan BJ 2007. Apoidea (Insecta: Hymenoptera). Lincoln, New Zealand, Manaaki Whenua Press. 295 p.

Donovan BJ, Howlett BG, Walker MK 2010. Relocation and establishment of nesting populations of the native bee Leioproctus huakiwi Donovan (Hymenoptera: Colletidae). New Zealand Entomologist 33: 109-113.

Garibaldi LA, Steffan-Dewenter I, Winfree R, Aizen MA, Bommarco R, Cunningham SA, Kremen C, Carvalheiro LG, Harder LD, Afik O, Bartomeus I, Benjamin F, Boreux V, Cariveau D, Chacoff NP, Dudenhoffer JH, Freitas BM, Ghazoul J, Greenleaf S, Hipolito J, Holzschuh A, Howlett B, Isaacs R, Javorek SK, Kennedy CM, Krewenka K, Krishnan S, Mandelik Y, Mayfield MM, Motzke I, Munyuli T, Nault BA, Otieno M, Petersen J, Pisanty G, Potts SG, Rader R, Ricketts TH, Rundlof M, Seymour CL, Schuepp C, Szentgyorgyi H, Taki H, Tscharntke T, Vergara CH, Viana BF, Wanger TC, Westphal C, Williams N, Klein AM 2013. Wild pollinators enhance fruit set of crops regardless of honey bee abundance. Science 339: 1608-1611.

Gathmann A, Tscharntke T 2002. Foraging ranges of solitary bees. Journal of Animal Ecology 71: 757-764.

Godley EJ 1979. Flower biology in New Zealand. New Zealand Journal of Botany 17: 441-466.

Goulson D 2003. Effects of introduced bees on native ecosystems. Annual Review of Ecology, Evolution, and Systematics 34: 1-26.

Greenleaf SS, Williams NM, Winfree R, Kremen C 2007. Bee foraging ranges and their relationship to body size. Oecologia 153: 589-596.

Howlett BG, Donovan BJ, McCallum JA, Newstrom LE, Teulon DAJ 2005. Between and within field variability of 
New Zealand indigenous flower visitors to onions. New Zealand Plant Protection 58: 213-218.

Howlett BG, Donovan BJ 2010. A review of New Zealand's deliberately introduced bee fauna: current status and potential impacts. New Zealand Entomologist 33:92-101.

HowlettBG, Walker MK, Rader R, Butler RC, Newstrom-Lloyd LE, Teulon DAJ 2011. Can insect body pollen counts be used to estimate pollen deposition on pak choi stigmas? New Zealand Plant Protection 64: 25-31.

Kelly D, Robertson AW, Ladley JJ,Anderson SH, McKenzie RJ 2006. The relative (un)importance of introduced animals as pollinators and dispersers of native plants. In: Allen RB, Lee WG eds. Biological invasions in New Zealand. Berlin, Springer. Pp. 227-245.

Kelly D, Ladley JJ, Robertson AW, Anderson SH, Wotton DM, Wiser SK 2010. Mutualisms with the wreckage of an avifauna: the status of bird pollination and fruit-dispersal in New Zealand. New Zealand Journal of Ecology 34: 66-85.

Kim J, Williams N, Kremen C 2006. Effects of cultivation and proximity to natural habitat on ground-nesting native bees in California sunflower fields. Journal of the Kansas Entomological Society 79: 309-320.

Klein A-M, Vaissière BE, Cane JH, Steffan-Dewenter I, Cunningham SA, Kremen C, Tscharntke T 2007. Importance of pollinators in changing landscapes for world crops. Proceedings of the Royal Society B. Biological Sciences 274: 303-313.

Lentini PE, Martin TG, Gibbons P, Fischer J, Cunningham SA 2012. Supporting wild pollinators in a temperate agricultural landscape: maintaining mosaics of natural features and production. Biological Conservation 149: 84-92.

Macfarlane RP 1992. An initial assessment of blueberry pollinators in New Zealand. New Zealand Journal of Crop and Horticultural Science 20: 91-95.

Macfarlane RP, Ferguson AM 1983. Kiwifruit pollination: a survey of the insect pollinators in New Zealand. Fifth International Symposium on Pollination, Versailles 27-30 September. Pp. 367-373.

MacIvor JS, Cabral JM, Packer L 2014. Pollen specialization by solitary bees in an urban environment. Urban Ecosystems 17: 139-147.

MoarNT 1993. Pollen grains of New Zealand. Dicotyledonous plants. Lincoln, Manaaki Whenua Press. 200 p.

Newstrom-Lloyd LE 2013. Pollination in New Zealand. In: Dymond JR ed. Ecosystem services in New Zealand. Lincoln, New Zealand, Manaaki Whenua Press. Pp. 408-432.

Newstrom L, Robertson A 2005. Progress in understanding pollination systems in New Zealand. New Zealand Journal of Botany 43: 1-59.

Editorial board member: David Pattemore

Received 4 July 2016; accepted 20 June 2017
Primack RB 1978. Variability in New Zealand montane and alpine pollinator assemblages. New Zealand Journal of Ecology 1: 66-73.

Primack RB 1983. Insect pollination in the New Zealand mountain flora. New Zealand Journal of Botany 21: 317-333.

Quinn P 1984. Survey of native bees (Hymenoptera, Colletidae and Halictidae) in the MacKenzie Basin. New Zealand Entomologist 8: 41-44.

R Development Core Team 2014. R: a language and environment for statistical computing. Version 3.1. The R Foundation for Statistical Computing. Vienna, Austria.

Rader R, Howlett BG, Cunningham SA, Westcott DA, Newstrom-Lloyd LE, Walker MK, Teulon DAJ, Edwards W 2009. Alternative pollinator taxa are equally efficient but not as effective as the honeybee in a mass flowering crop. Journal of Applied Ecology 46: 1080-1087.

Rader R, Edwards W, Westcott DA, Cunningham SA, Howlett BG 2011. Pollen transport differs among bees and flies in a human-modified landscape. Diversity and Distributions 17: 519-529.

Rader R, HowlettBG, Cunningham SA, Westcott DA, Edwards $\mathrm{W}$ 2012. Spatial and temporal variation in pollinator effectiveness: do unmanaged insects provide consistent pollination services to mass flowering crops? Journal of Applied Ecology 49: 126-134.

Read PEC, Donovan BJ, Schroeder NC 1990. Rearing and distribution of the introduced wasp parasitoid Sphecophaga vesparum throughout New Zealand. Forty-third New Zealand Weed and Pest Control Conference Proceedings. Pp. 191-194.

Robertson AW, Ladley JJ, Kelly D 2005. Effectiveness of shorttongued bees as pollinators of apparently ornithophilous New Zealand mistletoes. Austral Ecology 30: 298-309.

Stevenson MA, Benard H, Bolger P, Morris RS 2005. Spatial epidemiology of the Asian honey bee mite (Varroa destructor) in the North Island of New Zealand. Preventive Veterinary Medicine 71: 241-252.

Waser NM 1986. Flower constancy: definition, cause and measurement. American Naturalist 127: 593-603.

Webber CJ, Peterson AJ, Kelly D, Clemens J 2012. Native and exotic flower visitors in the Christchurch Botanic Gardens and their contrasting plant preferences. New Zealand Natural Sciences 37: 37-49.

Whitaker AH 1987. The roles of lizards in New Zealand plant reproductive strategies. New Zealand Journal of Botany 25: $315-328$

Wojcik VA, McBride JR 2012. Common factors influence bee foraging in urban and wildland landscapes. Urban Ecosystems 15: 581-598.

Zurbuchen A, Landert L, Klaiber J, Müller A, Hein S, Dorn S 2010. Maximum foraging ranges in solitary bees: only few individuals have the capability to cover long foraging distances. Biological Conservation 143: 669-676. 